\title{
MYTHS OF THE NORTH AND ORIGINS OF CITY-FORM: SOME REFLECTIONS ACROSS HISTORY AND PREHISTORY
}

\author{
Abraham AKKERMAN \\ Department of Geography and Planning, Department of Philosophy, University of Saskatchewan, \\ 117 Science Place, Kirk Hall 107, Saskatoon, Saskatchewan, S7N 5C8 Canada \\ E-mail:avi.akkerman@usask.ca
}

Received: 30 May 2015; accepted 01 July 2015

\begin{abstract}
Early environmental myths of the body and the sky have been instrumental in the emergence of prehistoric urban environments, and have continued to play an important role in urban design through history to this time. The notions of the body, as the absolutely immediate, and the sky, as the unreachably distant are shown here as precursors to the core proposition of mindenvironment transactions, introduced by Walter Benjamin a century ago. Late prehistory and early antiquity manifest the idea of epochal and ongoing progression in mind-city interaction, specifically, as a gender-based configuration of edifice versus space, or volume versus void, in the built environment. The North Star, as a celestial feature representing permanency and solidity, was critical in the formation of masculine myths of the environment upon which the very notion of a designed edifice had been founded, and from which the early city had emerged. The feminine counterpart of the edifice is urban void, often the garden, the street or the city square. Whereas in Neolithic communities the open ritual space seems to have been the most important design element, cityform since antiquity has habitually accentuated the masculinity of edifices over designed voids. More feminine attituted drawing on prehistoric acumen can help refocusing the emphasis on urban volume, onto dynamic urban design of open public spaces for human movement in the city.
\end{abstract}

Keywords: city, cultural heritage, good urbanism, legacy, metaphor, public open space, spirit of the place, urban landscape.

\section{Introduction}

Almost a century ago the French historian Marcel Poëte had suggested that the city is an organic hybrid of minds within their built environment (Poëte 1929). In his 1935 cinematic animation, Pour mieux comprendre, Poëte juxtaposed layouts of different capital cities in support of his claim that the history of each city is reflected in its layout and projected upon its city-form. Differences in current layouts between cities were said to inherently indicate also their different histories. On Poëte's view, it is the innate memory of an early settlement imprinted in its urban descendant centuries later that gives flair of a living organism to the city (Periton 2006).

About at the same time as Poëte was writing his essay on urban evolution, Walter Benjamin had suggested that since antiquity the city street has been a manifestation of the collective unconscious (Benjamin 1972: 46-47; Buck-Morrs 1990: 114). Through his lite- rary venture, the Arcades Project, Benjamin had made notes of his observations of European streetscapes, leading him to make the conjecture that civilization recreates its own environments through ideal, mythical images of earlier ages. It is also due to this process of continuing re-creation, he suggested, that twentieth century's modern city-form had emerged.

Benjamin's point in identifying myth as a creative force in the emergence of urban civilizations is certainly grounded in historical evidence. On the Italian and Peloponnese peninsulas magic rites were inherent to the founding of Etruscan cities and Roman towns, and many of the deified heroes of Greek mythology were founders of cities, and streets within newly founded Greek colonies were sometimes given names of deities. In myth, the founder of Tarquinia, Mantua and other Etruscan cities in the Po River Valley was Tarchon, the chief hero of the Etruscans (de Grummond 2006: 203), and in founding their cities Etruscans followed strict 
rules of divination (Pallottino 1942/1975: 154; Aveni, Romano 1994). The poet Virgil produced Rome's national epic, the Aeneid, which drew on myths that linked the city's founding with Greek deities and legends. Commenting on Rome's early origins the historian Livy in The Founding of the City noted, indeed: "The traditions of what happened prior to the foundation of the City or whilst it was being built, are more fitted to adorn the creations of the poet than the authentic records of the historian" (Mellor 2004: 120).

In Benjamin's eyes too, from the archaic town to twentieth century's metropolis, the street has evolved into a mythic medium through which new urban images have been generated and visions of an ideal city had emerged. Invoking the notion of the collective unconscious from the contemporaneous writings of Carl Jung, just a decade earlier, Benjamin had suggested that an ongoing interaction between the city and the minds within it takes place in a mutual feedback between two contrasting elements: The myth of an ideal urban world, against the reality of the authentic city street.

In an amalgam of urbanism and psychoanalysis Poëte and Benjamin had both alluded to a single hybrid of city and the minds within it. Continuous mutual impact between the built environment, on the one hand, and human bodies and minds within it, on the other hand, ought to be counted, on this view, as a force behind the evolution of urban civilizations. Some affinity in the departing point to this approach could be seen later in the phenomenology of the city by Maurice Merleau-Ponty (1962: 440), and in the architectural hermeneutics of Dalibor Vesely (2002: 28-43).

Perception of one's own body constitutes cognizance of a thing absolutely immediate to the self. Projection of such cognizance upon the construction of human built environments could be surmised as a subtle, unconscious, but collectively universal disposition of human beings (Akkerman 2006). On the other hand impact upon prehistoric urban settlements in myths emanating from early human observations of the $s k y$, had been discerned in the work of Giorgio de Santillana and Hertha von Dechend (1977). While some of the assertions made by Santillana - von Dechend have been considered unsubstantiated, attention to the impact of nightly sky observations upon prehistoric human settlements was also drawn by others, prominent among them being Edwin Krupp (1997: 196-199). The body and the sky, the absolutely immediate against the unreachably distant, have been the design motives behind early settlement structure and the primordial impulse to mind-city interaction.

The earliest stages of human settlement have been also the source of the myth of the ideal city, itself a powerful and ongoing psychic component in city building. The postulation of continuing and mutual feedback between mind and the built environment is thus directly associated with the stance that the origin of mind-environment interaction ought to be sought in a perceptual link between the absolutely immediate, the human body itself, and the unreachably distant of the three-dimensional spatiality, the sky. Such a proposition suggests, in effect, that the forces of this interaction have been ongoing, having led to the forging of our contemporary and very own built environments. Furthermore, the representations of the body, as the absolutely immediate, and of the sky, as the unreachably distant had been gender-based, and as such have been projected onto city-form. Gender-based urban representations were, on this view, at the origin of city building as the initial impetus setting in motion continuous environ/mental progression, and have been at play ever since, till contemporary city-form of the present day.

\section{Void and gynocentrism}

Focal attention to the human body is evident in Paleolithic and Neolithic stone art, particularly in the various Venus figurines produced through millennia over these periods.

The perceptual source that had led to the production of bodily statuettes had also contributed to the appearance of first settlements at the onset of the agricultural revolution, as suggested in findings of the Near-Eastern Natufian culture of north-central Israel, from about 12,000 before present. The birthplace of first agricultural endeavours were Natufian settlements which seem to have evolved also alongside a conscious focus on gender and sex. A Natufian stone statuette of a couple engaging in sexual intercourse is the oldest of its kind (Boyd, Cook 1993).

At Çatalhöyük, an urban settlement from 7000 BCE in the Anatolia region of present-day Turkey, abundance of excavated goddess statuettes point to egalitarian, and perhaps even matriarchal, culture (Mellaart 1967: 180181)... From archaeological excavations it emerges that, thousands of years later, the nearby Minoan civilization on the Mediterranean island of Crete had possessed a lasting communal disposition towards the female. It was the priestess, or a cult associated with one, that appears to have guided the Minoan civilization during the Bronze Age, c. 2700 BCE - c. 1500 BCE

In later mythology of Classical Greece, the flair of priestess is conferred on Pandora, the fabled primordial woman who attains supremacy, precisely, through her femininity: She is said to have opened a jar that contained toil, sickness, disease and all other ills 
of humans, releasing them all save one: hope. In the Greek creation myth Pandora appears to link the earth with the sky, herself being molded from earth, but created on order of Zeus, the god of the sky and thunder. Aspects of earth-based myths of the Earthmother have been seen as the origin of a range of cosmogony allegories (Gimbutas 1989). On the other hand too, many world-creation parables found their own origins in frequently masculine paradigms of the sky (Clackson 2007: 93). Consolidating in her priestess stature the earth and the sky, Pandora in the mythology of Classical Greece, had inspired shrines such as Delphi that had followed in the Minoan female priestess tradition.

The Minoan priestess ritual had been performed in sanctuaries at caves or at designed open spaces atop mountains, and archaeological finds traced to Minoan Crete point to a prominently gynocentric Minoan culture and religion (Kerényi 1976). An important feature of many Minoan peak sanctuaries on Crete, such as the open-air peak sanctuary on Mt. Iuktas and the adjacent palace at Knossos, is their alignment with adjacent palaces on a north-south axis (Marketou 1988: 28-31). Another sanctuary from about the same time, c. 2100 BCE, the sacred cave of Kamares at Mt. Ida, similarly, has a north-south alignment with the palace at Phaistos (Karetsou 2010).

Consistent with the numerous Minoan peak sanctuaries, a north-south orientation can also be found in many Egyptian pyramids, burial monuments constructed around the same time as, or a few hundred years earlier than the Minoan ritual spaces. At c. $2700 \mathrm{BCE}$ a north-south orientation would be attained most expediently by alignment with the star Alpha Draconis, or Thuban to the Egyptians, as the North Star. Alpha Draconis is a faint star of brightness 3.7, and even if it was brighter c. 2700 BCE than it is today, it still would have required an observational skill to be identified as the North Star. There are no bright stars in the sky vicinity of Alpha Draconis. To the Egyptians the dark area in the nightly sky in the vicinity of Alpha Draconis was considered void round which the rest of the universe revolves. After burial Pharao's soul was believed to ascend to the abode of gods, and some of the pyramids were designed specifically for the mythic purpose of launching the soul from its burial place through this celestial void.

There are no extant written records by the Minoans but it is fair to presume that, due to lack of any clearly visible stars about the celestial North Pole at the time, common Minoans might have considered the celestial north, a dark area round which the rest of the celestial sphere turns, as a great void. The configuration of Minoan ritual places, as open-air peak sanctuaries pointing to the north could be explained, thus, as an expedience to the priestesses linking the void in the sky with the female on Earth.

\section{Human posture and the nightly sky}

The prominence given to the female in the Minoan civilization seems to be, thus, related to the fact that at about $2700 \mathrm{BCE}$ there was no bright star in the sky vicinity of the north celestial pole. The well-established bond in creation myths between the female gender and the Earth, therefore, extends also to a similar bond with the sky. In their north-bound open spaces Minoan feminine cult provides an indication to the early impetus of a mind-environment feedback process, as relating gender with the observation of the sky.

A supporting notion to this link lies in the discovery of cranial fossils in Kenya at the turn of this century. In 2007 a group led by the respected anthropologist Fred Spoor published an article in the journal Nature pointing out that the cranial fossils' discovery is inconsistent with the conventional view of human evolution during the beginning of the Pleistocene (about 1,800,000 years ago), as a progression from Homo habilis to Homo erectus (Spoor et al. 2007). The article thus questions previously held opinions regarding some key aspects in the development of the genus Homo. Up until 2007 the conventional wisdom held that $H$. habilis, the first member of the genus Homo known to have used stone tools, was the evolutionary ancestor of the more human-appearing species, $H$. erectus. The anthropologists' conclusion, however, was that, instead of $H$. erectus being descended from $H$. habilis, the two species in fact coexisted as two separate lineages. This distinction is critical not only to anthropology, but also in throwing light on the later evolution of $H$. sapiens that had led, since the onset of the Holocene, the current geological epoch, some 12,000 years ago, to the founding of cities and to the emergence of civilization.

To the Roman poet Ovid, the erect man is the only creature that could imperturbably raise eyes towards the sky, "and with an upright face may view the stars" (Ovid 1916: 76). In addition to casual and ongoing observation of the sky upright posture and gait in humans facilitated also the capacity to measure distances for the methodical construction of shelter. Celestial observations and the mental ability to sort and assimilate them were the source that generated beliefs and superstitions, and may have come independently of the ability to make tools. The progression, in some anthropological accounts, from $H$. erectus to our very own ancestor, $H$. sapiens sapiens, some 150,000 years 
before present, lends support to the outlook that posture and gait, along with some observational opportunities in the nightly sky, had ultimately guided the rise of orderly settlements during the Neolithic.

From about 15,000 before present to about 10,000 bp, along and north of the Tropic of Cancer an inescapable observation could be made during the course of each starry night. Throughout this period of about 5,000 years at the turn of the Holocene, the evening sky north of the Tropic of Cancer had a salient feature in the almost permanent location of the star Alpha Lyrae in the nightly sky. Better known as Vega, in the constellation Lyra, during these five millennia the star had been in the close vicinity of the north celestial pole.

During a period of about 26,000 years, known as the precession of the equinoxes, the Earth's axis oscillates pointing to different parts of the sky, and to Polaris as the North Star of today. Even though it never comes closer than $5^{\circ}$ off the north celestial pole, the brilliant Vega at about 14,000 bp was the North Star. With its exceptional brightness ( 0.03 as measured in observational astronomy), Vega is the fifth brightest in the entire sky.

Other than experiencing gradual warming, people in the northern hemisphere at the onset of the Holocene had thus experienced another significant feature: each clear night throughout the entirety of a human life and across generations, Vega, observed from the vicinity of the Tropic of Cancer and anywhere north thereof, appeared as a permanent beacon in the nightly sky. To the naked eye and without much observational skill, Vega would come into sight at a constant celestial location, with the entire celestial sphere seemingly spinning around it. The millennia-old observational tradition of a bright North Star had continued to seek the North even during the period $2800 \mathrm{BCE}-2200 \mathrm{BCE}$ when in the vicinity of the north celestial pole were only faint stars, or darkness and void to the casual observer, marking a mythical feminine trait to the North.

\section{The pole star as a feature in early human settlement configuration}

It was also the verifiable observational tradition during millennia of the Late Pleistocene (120,000 bp - 15,000 bp) through which early modern humans north of the Tropic of Cancer watched the North Star as the pivot - the founding rock, so to speak, round which the rest of the sky revolves each calm night. Sporadic observation of the nightly sky may have started with $H$. erectus, setting in motion migration northward. A prominently visible pole star in the nightly sky would have marked direction for some of the migrating bands of humans. Once sedentary, human communities would continue to use the incumbent pole star, or a bright star in its vicinity, such as Vega at the onset of the Holocene, as an important navigation beacon. In the millennial-old observational tradition at the turn of the Neolithic era, the bright Vega, a fixed, flaring emblem of the nightly sky became also the mythical sign guiding the construction of first settlements.

Construction of sturdy shelter, further north of the Tropic of Cancer, became necessary to humans through the menace of the natural environment, not the least the winter cold, lightning, wind and rain, all attributable to the varying temper of the sky, alternating with spurts of scorching heat during the summer. The contrast between the existential threat in the ever changing fortunes of nature and human fate, versus the seemingly unchanging axle of the North Star as the cornerstone of the nightly sky, ultimately laid ground at the dawn of history for the mythic drive to found an ideal community, as a shelter in the image of the universe. The ensuing and mutually related myths of the Citadel and the Ideal City have been put forward as significant mental constituents in the history of cityform (Vico 1744/1968). Geomantic as well as practical significance in the construction of human settlements was assigned to the correspondingly advantageous, or adverse wind directions, sun angle and shadow patterns. Compass direction of settlements or edifices from China through the Indus Valley, Mesopotamia and the Near East, to Europe, as well as in northern and Central America would be guided by geomantic beliefs geared towards the sky.

Street orientation to the points of the compass, in particular, has been enshrined in urban environments throughout history. The first sign of systematic city planning is an orthogonal grid plan of straight streets appearing in Indus cities during the third millennium BCE. At Mohenjo-Daro in the Indus Valley, built sometime before $2600 \mathrm{BCE}$, twelve orthogonal city blocks measuring $35 \times 25 \mathrm{~m}$ were formed by three 9-meter-wide avenues and two streets crossing them at right angles. These very large blocks were subdivided by alleys up to $3 \mathrm{~m}$ wide onto which many of the houses opened. The three avenues were identified to run north and south, with corresponding positioning in the subdivision of street blocks. The orienting of Mohenjo-daro to the points of the compass and the street layout into twelve blocks, apparently corresponding to the twelve lunar months, suggests adherence to perceived cosmic order in early cities of the Indus Valley (Hawkes 1973: 271).

Adherence to cardinal directions in the layout of Mohenjo-daro repeats itself in other early cities as 
well, and the division into twelve blocks also appears in classical Greece. Recalling the layout of Mohanjo-daro, archaeological finds as well as later historical record of the first century BCE confirm at Thurii, southern Italy, four avenues running in one direction and three other streets at right angles to them:

The Sybarites who were driven a second time from their native city[...] received an oracular response from Apollo that they should found a city in the place where there would be water to drink in due measure, but bread to eat without measure. [...] Having found not far from Sybaris a spring called Thuria [...] and believing this to be the place which the god had pointed out, they threw a wall about it, and founding a city there they named it Thurium after the spring. They divided the city lengthwise by four streets the first of which they named Heracleia, the second Aphrodisia, the third Olympias, and the fourth Dionysias, and breadthwise they divided it by three streets, of which the first was named Heroa, the second Thuria, and the last Thurina. And since the quarters formed by these streets were filled with dwellings, the construction of the city appeared good.

(Diodorus Siculus 1989, IV, 12, 10)

Excavations have shown that also in Mesopotamia as well as in North and Central America the founding and layout of cities was linked with astronomical observations. Ancient sanctuaries too could be regarded as emulating the nightly sky with the northern star, or its surrogate, as its pivot. These early urban planning conventions have been preserved to as late as the building of Roman colonies and newly founded towns (Magli 2008).

\section{Axis mundi and masculinity}

A vivid manifestation of the link between early observations of the universe, the four cardinal directions, and the myth of the Ideal City are early ideographic symbols for 'city' and for 'sun': In Europe, throughout many cultures since prehistory, the encircled cross had stood for both City and Sun. Perhaps the most vivid evidence for the lasting mythical link between the two concepts is Heliopolis in Egypt, a city founded in the third millennium BCE, and the seventeenth century ideal city notion of Tomasso Campanella, the City of the Sun, complete with seven rings of concentric avenues, against the number of perceived celestial spheres, and four streets radiating from its centre in compass directions (Donno 1981).

Observation of the sky, or the solar disk in particular (at dusk or dawn, or its reflection in water), gave impetus to the first development of the wheel and its various usages from spindles to chariots. The link between the observation of the solar disk, and the manufacture of a spoked wheel, was the abstract idea of perfection expressed in a circle and a straight line, initially articulated in various sun chariot myths.

The wheel had been repeatedly invented, initially for making pottery, possibly as early as 10,000 BCE in China and North Africa, and 7,000 BCE in South America. Perhaps around the same time or somewhat later the wheel was applied as a spindle for spinning wool or other fibers into threads to make fabrics. The two-spoked and four-spoked chariot wheel was developed about 4,000 BCE in Mesopotamia and the Caucasus, and about the same time in Central Europe. The first known two-wheel carts appear to have been used in Mesopotamia at about 3000 BCE and twowheel chariots towed by drawing animals, were successfully used in combat in about 2800 BCE (Lay 1992: 28).

One of the most vivid demonstrations of myth as a conceptual basis to the wheeled chariot is the Biblical episode of Josiah (c. 649-609 BCE), King of Judah, instructing one of his officials at the entrance courtyard of the Temple of Solomon, to destroy chariots ordered by his grandfather, King Menasseh (r. 687-642 BCE), as symbols of paganism:

And he took away the horses that the kings of Judah had given to the sun, at the entering in of the house of the LORD, by the chamber of Nathanmelech the chamberlain, which was in the suburbs, and burned the chariots of the sun with fire.

(The Old Testament II Kings 23,11)

It is uncertain whether wheeled traffic came prior to roads, but street paving has been found from the first human settlements around $4000 \mathrm{BCE}$ at Mohenjodaro. It is clear, furthermore, that there had been a consideration of mutual utility, leading to ongoing improvements in the construction of both roads and carts, much as there was a cerebral process of feedback between observation of the solar disk, myths of the sun chariot, and the construction of actual wheels and chariots.

The initial and most important feature necessary for the construction of a wheel is the axle. In most mythologies involving the sun, or where the star Vega figures as related to the north, both celestial bodies imply masculine properties, the sun due to its power and strength, the North Star due to the idea of an axis round which the nightly universe revolves.

The axis mundi, as a world pillar, had variably represented the center of the world, or a physical link between the heaven and the earth. First manifest as a tree or a mountain, the axis mundi was ultimately represented by man-made structures, ladder or staff, 
towers and other tall buildings. Considered a masculine symbol, the axis mundi involves both the idea of a straight line, as well as that of a circle emerging from the geometry of compass directions. Cosmogony myths, accordingly, are observed as involving images of structures containing straight lines in a rotary motion, often perpendicular to each other. In an episode from the Hindu religious cosmogony tales, Puranas, gods are using Mount Mandara as a churning rod round which the serpent Vasuki is coiled. Gods grasping the serpent's tail and demons holding its head, twist Mount Mandara back and forth.

In the Hagiga Tractate of the Talmud, seven heavenly spheres are listed. The third of the spheres, Shehakim, is 'that in which millstones stand and grind manna for the righteous' (Steinsaltz 2012). The Nordic myth of Mundilfæri associates the turning of the cosmos via a 'mill-handle' with the regulation of seasons, and the myth of Bergelmir engages images of milling of a giant's body in a process of creation.

Mythic or shamanic notions of a world axis, implying masculine disposition, needed not involve the sun or the North Star. Perhaps the oldest extant example where cosmic myth meets practical expediency in urban design is orientation of dwellings at the Banpo site in the Yellow River Valley in central China. Some 200 pit houses at this Neolithic settlement of about $5 \mathrm{ha}$, dated to $4000-4500 \mathrm{BCE}$, are sited for solar gain by having their doors aligned to what was at the time the culmination of the Yingshi constellation of stars (corresponding to part of the western Pegasus constellation) shortly after the winter solstice (Pankenier 1995).

\section{Axial age civilizations as a project of north- hemispheric masculinity}

Frequent north-south alignment of burial places and sacrificial sites, and sky-bound geomancy in object configuration, had all direct or indirect impact upon the founding, layout and growth of cities at the dawn of history. Most or all of these prehistoric modules had occurred in the northern hemisphere. This leads to an inevitable question: While the emergence of $H$. sapiens sapiens, some 150,000 years ago, has been placed in southern and eastern Africa between the Equator and the Tropic of Capricorn (Almquist, Cronin 1975), why had the vast majority of urban civilizations evolved in the northern hemisphere?

By 20,000 bp both northern and southern hemisphere were inhabited by humans. Nevertheless, any brief survey of early civilizations shows immediately that evolution of human settlements into cities had occurred primarily in the northern hemisphere. The civilizations that seem to have determined most significantly the course of history on Earth, moreover, are all close to or north of the Tropic of Cancer. The majority of significant urban civilizations through prehistory and early antiquity had largely evolved along the Euro-Asian band between the 20th and the 30th parallel northern latitude. Karl Jaspers had referred to this North-Hemispheric Eurasian band, between 800 BCE and 200 BCE, as Axial Age Civilizations (Jaspers 1953; Schwarz 1975). More than a dozen civilizations could be easily counted during or prior to the first millennium BCE: Japan, Korea, China, Mongolia, Indus Valley, Mesopotamia (including Babylon), Assyria along with Phoenicia and Canaan, Israel, Egypt, Minoan, Mycenaean and Achaean, Classical Greece, and Rome. The Mexican civilization Olmec (later the Aztec and Maya) was near (but still north of) the Equator.

Only the Peruvian civilization of Norte Chico (and, much more recent, the Inca) were south of the Equator. The largest and the most important settlement of the Norte Chico civilization, and thus also the foremost in the southern hemisphere, is Caral (c. 2600 BCE - 2000 BCE). Caral may have drawn on the seventeen or-so surrounding settlements, giving impression of a developed agricultural society. Enclosing an area of some 66 hectares Caral shows no trace of streets, and it had probably never made the leap from a fort or a sanctuary into becoming a city. Amidst the findings on the Caral site there is also no evidence of workshops, or an ongoing pattern between residences and places of work. The Great Pyramid of Caral measures $160 \mathrm{~m}$ by $150 \mathrm{~m}$ and rises $18 \mathrm{~m}$ high. Yet in spite of its impressive display of temples and pyramids, Caral probably had never been a home to more than three thousand permanent residents, possibly priests and their servants. Even though variety of residential architecture was uncovered at the site there is much indication of open spaces that may have been deliberately designed. It is also largely due to no evident signs of warfare, that Caral might be most appropriately considered a colossal ceremonial or ritual site rather than a city. Absence of warfare also in the entire region surrounding Caral, in marked contrast with contemporaneous Mesopotamia, for example, suggests, furthermore, pastoralist communities in the surrounding settlements.

In putting such great emphasis on open public spaces Caral is reminiscent of the Minoan cultic, but even more so, of the later Israelite civic sites where open spaces may have carried more significance than buildings. Entirely analogously with the Israelite religious convention a millennium later, Norte Chico, in the account of one observer, has almost no visual arts, 
sculpture, or carving (Mann 2006: 199-212) As if void itself were to elicit respect, rather than objects filling it. The one major difference between these two distant cultures is literacy: there is much literary evidence regarding Israelite urban design and the use of public spaces in the Hebrew Bible, while Caral, and seemingly the entire Nor te Chico civilization, had no script. Thus, there exists also no documentary or literary evidence regarding the design or use of buildings or open spaces in Caral.

It is almost certain that Norte Chico, as an amalgam of horticultural or pastoral societies had little need for defense or complexity, and village, tribe or extended family left little room for mutual estrangement. In the Bible the need for shelter had arisen only following the expulsion from the Garden, and it had emerged at once with the discovery of reason and retreat to alienation. Also within the later confines of the small Israelite city the notion of the garden, transformed into an open, public place, signified a particular aspect of archetypal supposition. The open space emphasis in the design of Caral suggests a similar paradigm in its own built environment.

\section{The hemispheric split in gender projection and early built environments}

In The Civilization of the Goddess (1991) Marija Gimbutas contends that the primordial human society in Europe (and by implication, elsewhere too) was matristic with goddesses seen as setting social and behavioral standards. Only at the onset of the Bronze Age, in Gimbutas' opinion, was this society displaced by a patriarchal culture. Although matristic, or some other gynocentric cultures, have been shown, indeed, to have preceded some patriarchal societies of late prehistory (e.g., Zanotti 1982), many aspects of Gimbutas' argument have been disputed (e.g., Fleming 1969).

The alternative proposition that masculine disposition was the prevailing feature in human evolution on the Earth's finds support, in some masculine projections upon the progression and growth of urban civilizations along the geographical band surrounding the Tropic of Cancer. The other side of this argument is the claim that human evolution on the Earth's southern hemisphere had ensued from a more collaborative and feminine outlook which was expressed mainly in pastoralist communities, stressing void, as against volume, in their built environments.

Throughout early urban history open public spaces, or urban voids, as both a subtle expression of femininity and a link with the natural environment surrounding the city, have countered temples, secular buildings, or private edifices. But it seems that during the early development of civilization, northhemispheric settlements have been primarily typified through the construction of edifices and towers, whereas emphasis on open space, rather than on elaborate construction of buildings, had occurred in human settlements in the southern hemisphere.

To the extent that the pole star represents the masculine features of stability, solidity and solitude, so do the ensuing myths of the Heavenly Mill, the Citadel and the Ideal City. In equatorial latitudes or south of the Equator, where Vega was only seldom or never visible, such a masculine feature appears to be missing. All the same, the myth of the Heavenly Mill had emerged in the geographic band between China/the Indus Valley and Europe, but not in the southern hemisphere. It seems to be also the northern hemisphere where the masculine paradigm of the Citadel unfolds in early civilization into the Myth of the Ideal City. Only in the northern hemisphere are early notions of the Ideal City implicit in the design of prehistoric settlements to the directions of the compass.

The northern hemisphere is $60.7 \%$ water and $39.3 \%$ land. The southern hemisphere is about $80.9 \%$ water and $19.1 \%$ land. The land area north of the Tropic of Cancer and south of the North Polar Circle is about twice the entire land area south of the Equator, excluding Antarctica. Even though population density was likely higher in the northern than in the southern hemisphere, statistically still, in the course of early history, at least some urban cultures, perhaps 4 or 5, should have emerged south of the Equator, as against the dozen or so in the North. Yet barring Norte Chico, which may have had a land bridge to the North (or may not have been urbanized society at all), for the entire land mass south of the Equator, and certainly south of the Tropic of Capricorn, there is no record of urban civilizations during or prior to the first millennium BCE.

It seems that only in the northern hemisphere did early humans have the opportunity to juxtapose the comforting constancy of a pole star and the spinning of the surrounding celestial sphere, against the unexpectedness and peril of earthly nature. The orderliness of the nightly sky, against the mayhem of daily struggle with nature and other humans was at the founding of the environ/mental feedback, ultimately transmuting the Citadel into the myth of the Ideal City. Only in the northern hemisphere the pole star, and the nightly sky spinning about it, likely constituted the initial navigational beacon of migrating bands of humans, and guidance for the construction of many early settlements. Stars or constellations that could be linked to the North Star laid base to astrological 
beliefs and led to mythical conviction in the existence of an ideal community and an Ideal City.

No similar evidence of alignment to compass directions is reported from Caral or other pre-historic, southern hemispheric settlements. Yet around the year 12,000 BCE, while Vega was marking the north celestial pole, in the southern celestial hemisphere the star Canopus (known by its catalogue name, Alpha Carinae), as the second brightest (at magnitude -0.7) in the entire sky, north and south, was within $10^{\circ}$ of the south celestial pole; and around the year $4000 \mathrm{BCE}$ the 0.5 magnitude star Achernar (Alpha Eridani) came within about $8^{\circ}$ of the south celestial pole. Both stars, similar to Vega in brightness, and almost as close to the pole as Vega, evidently provided no similar utility in the sky of the southern hemisphere.

\section{Environmental paradigms of gender projection}

There are at least two reasons why the southern celestial pole played no role in the construction of south hemispheric settlements. The first reason is that much of the population throughout the southern hemisphere constituted pastoralist society with little need for regimentation against marauding bands of other humans. More favorable climatic conditions than north of the equator made it less necessary to store food for inclement season, and to create administration and infrastructure for its distribution. Identifying the South Pole, as a fixed point in the nightly sky, had no utility to pastoralist communities surrounded by abundance of food sources, and by other like communities.

The second reason for the lack of early human interest in the southern celestial pole is grounded in observational difficulty for the naked eye to identify the celestial South Pole. The two incumbent southern pole stars, Canopus and Achernar, both appear situated within the Milky Way, studded with medium bright stars. Achernar in fact is within the Milky Way Galaxy. The brightness of the two stars loses much of its effectiveness on the background of the Milky Way which also is brighter in the southern hemisphere than it is in the northern hemisphere. To humans of the early Holocene the celestial South Pole would be as difficult to find, due to the brightness of the Milky Way, as it would be to the naked eye observer today when there is no clearly visible star in the vicinity of the South Pole. In addition, the prominence of the southern pole stars throughout the precessional cycle is further diminished by the presence of numerous stars of first-order brightness magnitude that are nowhere near the celestial South Pole.

Common, still today, across the Andes is the belief in a quartered cosmos whereby the Milky Way bisects the nightly sky in one season and in another season it bisects it in a perpendicular fashion (Urton 1981). Yet no ideographic symbols similar to the sunwheel, nor allegories of a heavenly mill, have emerged in the Andes or anywhere else in the southern hemisphere. The south hemispheric nightly skies offer some magnificent asterisms, the Southern Cross constellation being one, but in the formative millennia of the early Holocene none of these constituted a constant feature similar to the North Star.

The one fixed characteristics of the nightly sky in the southern hemisphere, is plain darkness, or void itself. Darkness is the primordial quality of creation, as a common theme in Polynesian mythology, for example, where deity and creation are predicated on void or nothingness. Because the Milky Way is brighter in the southern hemisphere, the dark nebulae within it are more pronounced. Emblematic is the most prominent nebula in the Milky Way, the Coalsack Nebula, situated between, and contrasted by, the two brightest stars of the Southern Cross constellation.

Just as Vega had been an identifying, usually masculine theme for much of the northern hemispheric nightly sky, void could be said to be the nightly sky's paradigm of the southern hemisphere. If the northern star had impact on the design of north-hemispheric settlements, could not void be a feminine theme in the design of south-hemispheric built environments? The site of Caral, with its abundance of what appears as designed open space, seems to lend support to such contention. This is not to say that north-hemispheric city-form had no use or appreciation of urban voids. And certainly, no contrary claim can be made to the effect that south-hemispheric or equatorial settlements did not approve of large edifices. The agora in Ancient Greece, and the pyramids at Caral obviously prove that voids in the North, much as large structures in the South, were an ongoing consideration. But in the way of emphasis, the supposition can be made, the Southern design premise in human settlements seems to emphasize open space, or void, whereas the Northern paradigm seems to be the citadel, the urban object, the building, and the volume. The association with femininity and masculinity is imminent.

It is commonplace that whereas myths associated with the earth had been universally associated with a female deity, the pole star in the northern hemisphere had provided an opportunity for the formation of a masculine paradigm of a god, a builder of the universe, a cosmoplast. The pole star of the northern hemisphere thus provided also the primordial impetus to the notion of a perfect construction, a citadel and an ideal city, commencing a mutual feedback progression between minds and their built environments. 
Early city-form, associated with the sky, had a masculine predisposition, which has largely prevailed to the present day. However, to the extent that city-form includes urban voids, such as streets and squares, and not only edifices, it involves a feminine aspect as well. Masculine and feminine features could be thus said to be intertwined within city-form, much as masculine and feminine archetypes are mutually entangled in Jung's collective unconscious. In Jung's psychoanalysis archetypal symbolism of femininity and masculinity, Anima and Animus, are presumed to be conversely innate in men and in women, never mutually exclusionary but always interwoven. Since the rise of early built environments, volume and void had corresponded to masculine and feminine features, and still today could be said to be mutually intertwined within city-form. The early urban link between earth and sky myths, manifest in the tangle of voids and edifices, is quite analogous to the notion of interwoven gender paradigms in Jung's psychoanalysis.

Through twentieth century's modernity, in particular, masculine aspects of city-form have culminated, imposed upon streets that have become largely conduits of motorized traffic, rather than outlets of human movement, or upon squares that have metamorphosed into intersections where people have no business other than crossing them. The turn of this century has seen a welcome change in the emergence of space syntax models focused on the configuration of urban voids as a primary feature of urban genotypes (Hillier, Netto 2002; Peponis, Wineman 2002: 287). Jan Gehl's focus on design of public spaces presents example of urbanist attitude that comes to emphasize the flow of human movement in urban space (Gehl 2010: 9-30). Such attitude seems to constitute a considered attempt to return to the primordial sources of city-form, whereby feminine aspects, urban voids in particular, receive a prominent attention. Expressing urban voids as the focal, feminine, features of city-form, is an outlook that pays tribute to millennia-old disposition towards gender imprints in city-form. This is a challenge that urban planning, design and architecture ought to recognize and internalize.

\section{Summary and conclusions}

A century ago, Marcel Poëte and Walter Benjamin had fused urban design with psychoanalysis. In pointing out that since antiquity a representation of the collective unconscious has been the city street, Benjamin surmised that urban civilization has been largely shaped in a feedback interaction of two contrasting urbanist features: one of the mind, the other of the environment. The one feature has been the myth of an ideal urban world; the other has been the reality of the authentic city street. The present study has expanded on Benjamin's notion in showing the gender aspects of the environ/mental interaction, and examining its meaning for urban planning and design in their historical and cultural missions.

The myth of an ideal city originates in two primordial paradigms: The one paradigm draws on the human body as an entity absolutely immediate to the human subject; the other paradigm arises from the nightly sky as a domain unreachably distant. The first paradigm addresses voids and volumes as feminine and masculine expressions of city-form, and is somewhat close to Merleau-Ponty's phenomenology of the city. The other paradigm ensues from considerations of myth in early human observations of the sky, where studies have pointed to the impact of nightly sky observations upon prehistoric human settlements (Santillana, von Dechend 1977; Krupp 1979: 196-199).

The very earliest pattern identified in the sky of the northern hemisphere was the permanency of the North Star, as a pivot round which the celestial dome revolves each night. The earliest identification of the north celestial pole, and the northerly direction, thus, would have been through the pole star. From about $15,000 \mathrm{BCE}$ to about 10,000 BCE, at the turn of the Holocene, along and north of the Tropic of Cancer an inescapable observation could be made during the course of each starry night. Throughout this period of about 5,000 years the evening sky north of the Tropic of Cancer had a salient feature in the almost permanent location of the star Alpha Lyrae, better known as Vega. The prominently masculine myths of the world axis (axis mundi) from China through Indus Valley to Europe have their origins in observation of Vega, as the North Star during this early Holocene period. Later on, layout of Neolithic long houses, and early planning of Bronze Age settlements had been founded on cardinal directions, always identifiable through the pole star. Settlement layout in cardinal directions, as a masculine feature have been frequent in early human settlement configuration, from Mohenjo-daro, in the Indus Valley of the third millennium BCE, to the Greek colony Thurii, founded in fifth century BCE.

Expressions of femininity linked to the nightly sky, on the other hand, are some Egyptian pyramids, built in the third millennium BCE, that were designed specifically for the mythic purpose of launching the soul from its burial place through to celestial void, marked by darkness in the region of the north celestial pole. During the third millennium BCE there was no prominent North Star in the nightly sky, and this was, therefore, a permanent feature of Ancient Egypt's nightly sky 
during at least a thousand years. During this period too Minoan sanctuaries of female priestesses were built in a north-south directions, thus aiming at the darkness surrounding the north celestial pole.

Carl Jung's feminine and masculine paradigms of the human unconscious, Anima and Animus, can be thus drawn as analogies to the celestial void and to the North Star, respectively, while urban spaces and urban edifices, voids and volumes, can be seen as representing the same analogies in city-form. Throughout urban history open public spaces, or urban voids, as both a subtle expression of femininity and a link with the natural environment surrounding the city, have countered temples, secular buildings, or private edifices. But it was almost always the masculine volume, the urban structure, rather than urban void, that have featured most prominently in city-form throughout history, and throughout the Northern Hemisphere.

Yet urban voids, streets, squares and small urban spaces, have always been the feminine face of city-form. Inherently projected onto geographical space by the cerebral makeup of humans, the significance of voids as design features in human settlements reaches deep into prehistory. Twentieth century's modernity has often relegated urban voids to the functional conduit of traffic, rather than internalizing their potential as constructive design elements. Urban voids, increasingly recognized as deserving as much attention in urban planning and design as buildings have received in architecture, carry also an important feature of a gendered civilization: their stature as equals to edifices not only constitutes a better city-form, but it also marks the linkage with our urban history and prehistory.

\section{Acknowledgments}

Thanks are due to two anonymous referees of this journal for their insightful comments and constructive criticism on the earlier version of this paper.

\section{References}

Akkerman, A. 2006. Femininity and masculinity in city-form: Philosophical urbanism as a history of consciousness, Human Studies 29(2): 229-256. http://dx.doi.org/10.1007/ s10746-006-9019-4

Almquist, A. J.; Cronin, J. E. 1975. Origin of man: problems in the interpretation of new evidence. Washington: American Association for the Advancement of Science.

Aveni, A.; Romano, G. 1994. Orientation and Etruscan ritual, Antiquity 68: 545-563.

Benjamin, W. 1972. Das Passagen-Werk, Vol. V, in R. Tiedemann, H.Schweppenhäuser, Th. Adorno, G. Scholem. Gasammelte Schriften. Frankfurt am Main: Suhrkamp Verlag.
Boyd, B.; Cook, J. 1993. A reconsideration of the "Ain Sakhri" figurine, Proceedings of the Prehistoric Society 59: 399-405. http://dx.doi.org/10.1017/S0079497X0000387X

Buck-Morrs, S. 1990. The dialectics of seeing: Walter Benjamin and the Arcades Project. Cambridge: MIT Press.

Clackson, J. 2007. Indo-European linguistics: an introduction. Cambridge: Cambridge University Press. http://dx.doi.org/10.1017/CBO9780511808616

de Grummond, N. Th. 2006. Etruscan myth, sacred history, and legend. Philadelphia: University of Pennsylvania Museum of Archaeology and Anthropology.

Diodorus Siculus. 1989. Bibliotheca historica [Diodorus of Sicily: historical library]. Translated by Oldfather, C. H. Cambridge and London: Harvard University Press.

Donno, D. J. 1981. The city of the sun: a poetical dialogue by brother Tommaso Campanella. Berkeley: University of California Press.

Fleming, A. 1969. The myth of the Mother Goddess, World Archaeology 1(2): 247-61. http://dx.doi.org/10.1080/00438 243.1969.9979443

Gehl, J. 2010. Cities for People. Washington: Island Press.

Gimbutas, M. 1989. The Language of the Goddess. San Francisco: Harper.

Gimbutas, M. 1991. The Civilization of the Goddess. San Francisco: Harper.

Hawkes, J. H. 1973. The First Great Civilizations. London: Hutchinson.

Hillier, B.; Netto, V. 2002. Society seen through the prism of space: Outline of a theory of society and space, Urban Design International 7(3-4): 181-203. http://dx.doi. org/10.1057/palgrave.udi.9000077

Jaspers, K. 1953. The origin and goal of history. Translated by Michael Bullock. London: Routledge and Keegan Paul.

Karetsou, A. 2010. Popular cult and power: the function of the Juktas Peak Sanctuary in Protopalatial and Neopalatial Crete. Dublin: Trinity College.

Kerényi, K. 1976. Dionysos: archetypal image of indestructible life. Princeton: Bollingen.

Krupp, E. C. 1997. Skywatchers, shamans and kings. John Wiley and Sons.

Lay, M. G. 1992. Ways of the World. Sydney: Primavera Press.

Magli, G. 2008. On the orientation of Roman towns in Italy, Oxford Journal of Archaeology 27(1): 63-71.

Mann, C. C. 2006. 1491: new revelations of the Americas before Columbus. Vintage Books.

Marketou, T. 1988. New evidence on the topography and site history of prehistoric Ialysos, in Soren Dietz and Ioannis Papachristodoulou (eds.). Archaeology in the Dodecanese. Copenhagen: The National Museum of Denmark, Department of Near Eastern and Classical Antiquities.

Mellaart, J. 1967. Catal Huyuk: a neolithic town in Anatolia. McGraw-Hill.

Mellor, R. 2004. The historians of Ancient Rome: an anthology of the major writings. Oxon: Routledge.

Merleau-Ponty, M. 1962. Phenomenology of perception. Translated by Colin Smith. New York: Humanities Press; London: Routledge \& Kegan Paul. 
More, T. 1516/2001. Discourses of Raphael Hythloday, of the best state of a commonwealth, in Utopia. New Haven: Yale University Press.

Ovid (Publius Ovidius Naso). 1916. Metamorphoses. Translated by Frank Justus Miller. London: W. Heinemann.

Pankenier, D. W. 1995. The cosmo-political background of Heaven's mandate, Early China 20: 121-176.

Periton, D. 2006. Generative history: Marcel Poëte and the city as urban organism, Journal of Architecture 11: 425-439. http://dx.doi.org/10.1080/13602360601037834

Pallottino, M. 1942/1975. The Etruscans. Bloomington: Indiana University Press.

Peponis, J.; Wineman, J. 2002. Spatial structure of environment and behavior, in: R. B. Bechtel and A. Churchman (eds.). Handbook of Environmental Psychology. New York: Wiley, 271-291.

Poëte, M. 1929. Introduction a l'urbanisme. Paris: Edition Anthropos.

Santillana, G. de; von Dechend, H. 1977. Hamlet's Mill: an essay on myth and the frame of time. Boston: Godine.

Schwarz, B. I. 1975. The age of transcendence, Daedalus (Special Issue: Wisdom, Revelation, and Doubt: Perspectives on the First Millennium BCE) 104(2): 1-7.

Spoor, F.; Leakey, M. G.; Gathogo, P. N.; Brown, F. H.; Antón, S. C.; McDougall, I.; Kiarie, C.; Manthi, F. K.; Leakey, L. N. 2007. Implications of new early Homo fossils from Ileret, east of Lake Turkana, Kenya, Nature 448: 688-691. http://dx.doi.org/10.1038/nature05986

Steinsaltz, A. 2012. Koren Talmud Bavli, Tractate Hagigah. Jerusalem: Koren Publishers.

Urton, G. 1981. At the crossroads of the earth and the sky: An Andean cosmology. Austin: University of Texas.

Vesely, D. 2002. The architectonics of embodiment, in G. Dodds, R. Tavernors (eds.). Body and building: essays on the changing relation of body and architecture. Cambridge: MIT Press.

Vico, G. 1744/1968. Scienza Nuova, II, 370, in Th. G. Bergin and M. H. Fisch. The New Science of Giambattista Vico. $3^{\text {rd }}$ ed. Ithaca: Cornell University Press.

Zanotti, D. G. 1982. The evidence for Kurgan Wave One as reflected by the distribution of 'Old Europe' gold pendants, Journal of Indo-European Studies 10: 223-234.

\section{ABRAHAM AKKERMAN}

Department of Geography and Planning, Department of Philosophy, University of Saskatchewan, 117 Science Place, Kirk Hall 107, Saskatoon, Saskatchewan, S7N 5C8 Canada E-mail:avi.akkerman@usask.ca

Professor in the Department of Geography and Planning at the University of Saskatchewan, Associate Member in the Department of Philosophy, a member of the Canadian Institute of Planners. He has written articles in professional journals, e. g., GeoJournal, Studia Phaenomenologica etc. Research interests: the juncture of urban planning, psychoanalysis, and philosophy, and also demography and urban transportation. 